\title{
Effective Reduction of Chimeric Tissue in Transgenics for the Stable Genetic Transformation of Lesquerella fendleri
}

\author{
Grace Q. Chen \\ Western Regional Research Center, Agricultural Research Service, U.S. \\ Department of Agriculture, 800 Buchanan Street, Albany, CA 95710
}

Additional index words. Lesquerella fendleri, Agrobacterium-mediated transformation, $\beta$-glucuronidase, hygromycine phosphotransferase II, shoot regeneration, chimera, segregation analysis

\begin{abstract}
To improve the potential of Lesquerella fendleri as a valuable industrial oilseed crop, a stable genetic transformation system was developed. Genetic transformation was performed by inoculating leaf segments with an Agrobacterium tumefaciens strain AGL1 containing binary vector PCAMBIA 1301.1, which contains a $\beta$-glucuronidase gene as a reporter gene and hygromycine phosphotransferase II as a selection marker gene. Primary shoots were regenerated from the leaf segments on the half-strength Murashige and Skoog (MS) medium supplemented with 6-benzylaminopurine, 1-naphthaleneacetic acid, and hygromycin. The frequency of primary shoot generation was between $22.5 \%$ and $60 \%$, and $81.1 \%$ to $89.3 \%$ of these shoots were chimeras. The high frequency of chimeras was probably the result of efficient protection from the hygromycin of nontransformed cells by adjacent transformed ones. The non-transformed cells were removed by multiple rounds of successive shoot regenerations. The purified isogenic shoots were subcultured and roots were induced on the MS medium plus indole-3-butyric acid. Most of the plantlets were able to establish roots and acclimate successfully in the greenhouse. The insertion of the hptII gene was confirmed by segregation analysis in $\mathrm{T} 1$ seeds, and the stable inheritance of the transgenes was demonstrated by the characterization transgenic lines through $\mathrm{T} 2$ generation. This transformation system can be used to obtain stable transgenic lines for genetic engineering of $L$. fendleri.
\end{abstract}

A conventional source of hydroxyl fatty acid (HFA) is castor oil that contains $90 \%$ ricinoleic acid (12-hydroxy-octadec-cis-9enoic acid:18:1OH). Ricinoleic acid and its derivatives are used as raw materials for numerous industrial products such as lubricants, plasticizers, and surfactants (Caupin, 1997). The production of castor oil, however, is hampered by the presence of the toxin ricin and hyperallergenic $2 \mathrm{~S}$ albumins in its seed. Lesquerella fendleri (A. Gray) S. Wats. (Brassicaceae), under development as a new industrial oilseed crop in the southwestern region of the United States, is valued for its unusual HFA in seed. The majority of HFA in L. fendleri is lesquerolic acid (14hydroxy-eicos-cis-11-enoic acid: 20:1OH) (Smith et al., 1961) comprising 55\% to $60 \%$ of total seed fatty acids (Dierig et al., 2001;

Received for publication 6 Oct. 2010. Accepted for publication 2 Nov. 2010.

The work was supported by the USDA-ARS Current Research Information System (CRIS) Project 5325-2100-016-00D.

I thank Colleen McMahan, Debbie LaudenciaChingcuanco, Kent McCue, and Niu Dong for critical reading of the manuscript; and Louisa Vang and Xianfang Meng for help in tissue culture and transformation work. Thanks are extended to Dr. David Dierig for kindly supplying the $L$. fendleri seeds.

e-mail grace.chen@ars.usda.gov. the transformation system reported here provides a useful means to achieving stable genetic transformation in L. fendleri.

\section{Materials and Methods}

Plant material, bacterial strain, and general growth conditions. The L. fendleri seeds, WCL-LY2 (Dierig et al., 2001), were kindly provided by Dr. Dave Dierig (USDAARS, Arid-Land Agricultural Research Center, Maricopa, AZ). Plants were grown in a greenhouse at temperatures between $28{ }^{\circ} \mathrm{C}$ (day) and $18{ }^{\circ} \mathrm{C}$ (night) with supplemental metal halide lighting to provide a 15 -h daylength (1000 to $\left.1250 \mu \mathrm{mol} \cdot \mathrm{m}^{-2} \cdot \mathrm{s}^{-1}\right)$. Mature flowers were hand-pollinated and the seeds were harvested at $\approx 49 \mathrm{~d}$ after pollination. An Agrobacterium tumefaciens strain AGL1 (Lazo et al., 1991) carrying binary vector pCAMBIA 1301.1 (http://www.cambia.org), which contains a gusA as a reporter gene and a hygromycin phosphotransferase II (hptII) as a selection marker gene, was used for plant transformation. An AGL1/pCAMBIA1301.1 culture was started with the inoculation of one clone in $1 \mathrm{~mL}$ Luria Bertani $\left(\mathrm{LB}, 10 \mathrm{~g} \cdot \mathrm{L}^{-1}\right.$ tryptone, $5 \mathrm{~g} \cdot \mathrm{L}^{-1}$ yeast extract, $5 \mathrm{~g} \cdot \mathrm{L}^{-1}$ sodium chloride, $1 \mathrm{~g} \cdot \mathrm{L}^{-1}$ glucose, $\mathrm{pH}$ 7) supplemented with $50 \mathrm{mg} \cdot \mathrm{L}^{-1}$ kanamycin and 100 $\mathrm{mg} \cdot \mathrm{L}^{-1}$ carbenicillin shaken at $200 \mathrm{rpm}$ overnight at $29{ }^{\circ} \mathrm{C}$ followed by subculturing of 0 . $1 \mathrm{~mL}$ of the overnight culture in $50 \mathrm{~mL}$ fresh LB for $24 \mathrm{~h}$. A control culture of AGL1 without pCAMBIA1301.1 was grown in LB plus $100 \mathrm{mg} \cdot \mathrm{L}^{-1}$ carbenicillin.

Tissue culture, transformation, and regeneration. Agrobacterium cultures were centrifuged at $4000 \mathrm{rpm}$ for $10 \mathrm{~min}$ at room temperature $\left(25^{\circ} \mathrm{C}\right)$ and the pellet was suspended to an $\mathrm{OD}_{600}$ of 0.5 in half-strength MS liquid medium (Murashige and Skoog, 1962). L. fendleri seeds were surface-sterilized in a $0.25 \%(\mathrm{v} / \mathrm{v})$ sodium hypochlorite solution for $15 \mathrm{~min}$ followed by five rinses in sterile deionized water. The seeds were germinated and grown aseptically on germination medium (GM) containing half-strength MS medium supplemented with $0.5 \%$ sucrose and $0.6 \%$ agar in a growth chamber at a day/night cycle $\left(16 / 8 \mathrm{~h}, 100 \mu \mathrm{mol} \cdot \mathrm{m}^{-2} \cdot \mathrm{s}^{-1}\right)$ at $24{ }^{\circ} \mathrm{C}$ (day) and $22{ }^{\circ} \mathrm{C}$ (night). After 4 to 6 weeks, shoot tips together with four to five true leaves were subcultured and grown aseptically on GM for a continuous supply of leaf material.

To perform the transformation, leaves were harvested from plants after 4 to 6 weeks of subculturing and wounded by scratching slightly on the underside of the leaf and then dipped in the half-strength MS medium containing AGL1/pCAMBIA1301.1 for $5 \mathrm{~min}$. After the inoculation, leaves were blotted on sterilized filter paper and transferred to callus and shoot induction (CSI) medium composed of basal medium (BM, half-strength MS medium plus $30 \mathrm{~g} \cdot \mathrm{L}^{-1}$ sucrose and $6 \mathrm{~g} \cdot \mathrm{L}^{-1}$ agar, $\mathrm{pH}$ 5.7) supplemented with $1 \mathrm{mg} \cdot \mathrm{L}^{-1} 6$ benzylaminopurine (BA) and $0.1 \mathrm{mg} \cdot \mathrm{L}^{-1} 1$ naphthaleneacetic acid. After incubating the infected leaves in the growth chamber for $2 \mathrm{~d}$, 
the leaves were cut into 5-mm segments and cultured on CSI media plus $25 \mathrm{mg} \cdot \mathrm{L}^{-1}$ hygromycin for transgenic selection and $100 \mathrm{mg} \cdot \mathrm{L}^{-1}$ timentin for inhibiting the Agrobacterium growth. For controls, samples were inoculated with AGL1 and leaf segments were placed either on CSI plus $100 \mathrm{mg} \cdot \mathrm{L}^{-1}$ timentine (positive control) or CSI plus $25 \mathrm{mg} \cdot \mathrm{L}^{-1}$ hygromycin and $100 \mathrm{mg} \cdot \mathrm{L}^{-1}$ timentine (negative control). Positive control samples initiated green calli on the edges of leaf segments in 2 weeks and then vigorously produced multiple shoots from the calli in 4 weeks, whereas negative control leaf segments displayed necrosis in 2 weeks and then died out in 4 weeks. For the transformed samples, yellow-greenish hygromycin-resistant (hyg ${ }^{\mathrm{R}}$ ) calli started to appear in 6 to 8 weeks on leaf segments. The calli were than transferred to a timentin-free subculture medium CSI+ (CSI with hygromycin increased to $50 \mathrm{mg} \cdot \mathrm{L}^{-1}$ ). Green shoots were developed from the calli on CSI+ medium in $\approx 2$ to 4 weeks after the transfer.

To eliminate chimeras, each shoot was cut into small pieces $(\approx 1 \times 1 \mathrm{~mm})$ and placed on the CSI+ medium for shoot regeneration. After four rounds of successive regenerations, shoots were subcultured on BM plus $1 \mathrm{mg} \cdot \mathrm{L}^{-1} \mathrm{BA}, 1 \mathrm{mg} \cdot \mathrm{L}^{-1}$ indole-3-butyric acid (IBA) and $50 \mathrm{mg} \cdot \mathrm{L}^{-1}$ hygromycin for multiplication. Shoots 10 to $15 \mathrm{~mm}$ in length were transferred to rooting medium (BM plus $1 \mathrm{mg} \cdot \mathrm{L}^{-1}$ IBA and $50 \mathrm{mg} \cdot \mathrm{L}^{-1}$ hygromycin). When a shoot developed two to three roots (usually in 3 to 5 weeks), it was than transferred to a Magenta box (Sigma, St. Louis, MO) containing sterilized peat-vermiculite growth mixture (Sunshine mix \#4; Planet Natural, Bozeman, MT) pre-soaked with $1 \mathrm{mg} \cdot \mathrm{L}^{-1}$ IBA water solution. After 8 to 10 weeks in the growth mixture, a well-developed plant showing eight to 12 normal leaves and 2- to 3-inch height was transferred to a 6 -inch pot and placed under a transparent plastic cover for the first 2 weeks for acclimation in the greenhouse.

Histochemical $\beta$-glucuronidase assay, chimera determination, and T1 and T2 plant verification. Histochemical $\beta$-glucuronidase (GUS) assays were performed using the Jefferson method (Jefferson et al., 1987). The assay solution contained $0.5 \mathrm{~mm}$ potassium ferrocyanide, $0.3 \%(\mathrm{v} / \mathrm{v})$ triton $\mathrm{X}-100$, and $1 \mathrm{mg} \cdot \mathrm{mL}^{-1}$ 5-bromo-4-chloro-3-indolylD-glucuronide (X-gluc) in $50 \mathrm{~mm}$ phosphate buffer, $\mathrm{pH}$ 7.0. Samples were incubated at $37^{\circ} \mathrm{C}$ overnight in the assay solution and then transferred to $70 \%$ ethanol to wash away chlorophyll for observation of blue GUS staining.

For chimera determination, GUS assays were performed on 10 randomly selected shoots derived from each line after 4 weeks of regeneration. A chimeric line was determined if one or more shoots were found to be a mixture of transformed cells (blue) and nontransformed cells (white). To test T1 seeds, T1 seeds were surface-sterilized as stated previously and placed in $\mathrm{GM}$ plus $50 \mathrm{mg} \cdot \mathrm{L}^{-1}$ hygromycin. $\mathrm{Hyg}^{\mathrm{R}}$ or hygromycin-sensitive (hyg ${ }^{\mathrm{S}}$ ) seedlings were documented after 2 weeks of culture in the growth chamber. Eight to 10 leaf discs (4-mm diameter) from each seedling were pooled and submerged in the GUS assay buffer in an enclosed test tube. The tube was then incubated overnight at $37{ }^{\circ} \mathrm{C}$ followed by washing in $70 \%$ ethanol. GUSstained tissue was observed after the chlorophyll was washed away. Because L. fendleri requires hand-pollination in the greenhouse to produce seeds, all seeds from greenhouse plants were produced by hand-pollination. Approximately $35 \mathrm{~d}$ after pollination, developing T2 seeds were tested for their GUS activities through the procedure described.

\section{Results}

Transformation and elimination of chimeras. In L. fendleri, leaf segments are highly prolific in shoot regeneration, and the protocols for tobacco transformation can be easily adapted. In three independent studies, control experiments were performed in the selection medium with (negative control) or without (positive control) $25 \mathrm{mg} \cdot \mathrm{L}^{-1}$ hygromycin. All 60 leaf segments from the negative control condition died out in 4 weeks showing complete bleaching (or necrosis), whereas 60 positive control leaf segments all produced green calli on the segment edges in 2 weeks. Approximately $92 \%$ of these leaf segments (55 of 60) quickly regenerated shoots (two to five per segment) within 2 to 4 weeks of culture. For leaf segments treated with AGL1/ pCAMBIA 1301.1, hyg ${ }^{\mathrm{R}}$ calli with yellowgreenish color appeared on leaf segments after 4 to 6 weeks of culture. The percentage of hyg $^{\mathrm{R}}$ calli generated from 80 treated leaf segments varied from $28.8 \%$ to $71.3 \%$ in three independent experiments (Table 1). Two to 4 weeks after transferring the calli to $\mathrm{CSI}+$ medium, most of the calli generated one primary shoot and a few generated zero or two primary shoots. So the overall primary shoot generation to leaf segments ratio was between $22.5 \%$ and $60 \%$.

Because chimeras were reported in $L$. fendleri transformation (Skarjinskaia et al., 2003; Wang et al., 2008), a procedure was developed to eliminate the chimeras or to produce isogenic transformants through multiple rounds of shoot regenerations. The percentage of chimeras was evaluated using a GUS assay after each round of regeneration. For example, after the first round, it was estimated that the majority of the primary hyg $^{\mathrm{R}}$ shoots were chimeras $(81.1 \%$ to $89.3 \%$; Table 1; Fig. 1C), whereas $8.7 \%$ to $16.7 \%$ were escapes (non-transgenic) (Fig. 1A) and only $1.7 \%$ to $2.2 \%$ were pure (or isogenic) transformants (Fig. 1B). The chimeras then went through multiple rounds of regeneration processes until no heterogeneous GUS stain could be found from randomly selected regenerated shoots. After four rounds of successive regenerations, the percentage of chimeras dropped to $1.4 \%$ to $2.2 \%$ (Table 1 ).

Pure transgenic shoots were subcultured and roots induced on basal medium plus 1 $\mathrm{mg} \cdot \mathrm{L}^{-1}$ IBA. Transgenic plants were subsequently established by transferring the plantlets with two to three roots to a sterilized peat-vermiculite growth mixture and cultivating for 8 to 10 weeks. Approximately $81 \%$ (152 of 188) of the plantlets reached 2- to 3 inch height and each had eight to 12 normal leaves. By transferring the established plants together with the growth mixture, 151 of 152 of plants representing 82 independent lines acclimated successfully in the greenhouse. Most of the lines were morphologically normal with the exception of one male-sterile line showing no stamens and two bushy lines with compact structure. Using GUS assays on leaf samples of each line, one GUS negative line (escape) was found. Because L. fendleri depends on insect pollination in the field, the remaining $78 \mathrm{~T} 0$ lines, which were morphologically normal and also GUS-positive, were hand-pollinated. All lines produced hybrid seeds. Among them, 12 lines were also capable of producing self-mate (selfed) seeds, which were further carried on for genetic analysis.

Genetic analysis in $T 1$ and $T 2$ progenies. The number of transgene insertions was determined by segregation analyses based on hptII gene activity in the T1 progenies of the 12 selfed T0 plants. Because hptII is a dominant gene, it follows a Mendelian phenotype segregation ratio of $3: 1\left(\operatorname{hyg}^{\mathrm{R}}: \mathrm{hyg}^{\mathrm{S}}\right.$ ) for one locus, 15:1 for two, and 63:1 for three loci. Segregations of hptII were examined by scoring the hyg $^{\mathrm{R}}$ (Fig. 2A) or hyg ${ }^{\mathrm{S}}$ (Fig. 2C) phenotype in $\mathrm{T} 1$ seedlings. The results are summarized in Table 2. Seven lines, 149, $174,178,213,312,324$, and 344, had a segregation ratio close to $3: 1$ indicating one hptII insertion locus, whereas Lines 350, 376, and 378 had a ratio close to $15: 1$ indicating

Table 1. Number of calli and shoots produced in leaf segments and percentage of chimera at each round of regeneration.

\begin{tabular}{lccccccc}
\hline \multirow{2}{*}{$\begin{array}{l}\text { Expt. } \\
\text { no. }\end{array}$} & $\begin{array}{c}\text { No. of } \\
\text { segments }\end{array}$ & $\begin{array}{c}\text { No. of } \\
\text { calliz }^{\mathrm{z}}\end{array}$ & \multirow{2}{*}{$\begin{array}{c}\text { No. of } \\
\text { shoots }^{\mathrm{y}}\end{array}$} & \multicolumn{3}{c}{ Percentage of chimeras at each round of regeneration } \\
\cline { 5 - 7 }
\end{tabular}

${ }^{z}$ The number was scored at the eighth week after placed on callus and shoot induction medium plus 25 $\mathrm{mg} \cdot \mathrm{L}^{-1}$ hyg and $100 \mathrm{mg} \cdot \mathrm{L}^{-1}$ timentin.

${ }^{\mathrm{y}}$ The number was scored at the fourth week of subculture on callus and shoot induction medium plus 50 $\mathrm{mg} \cdot \mathrm{L}^{-1}$ hyg.

${ }^{\mathrm{x}}$ Ten randomly selected shoots after 4 weeks of each round of regeneration were pooled from each line and tested by $\beta$-glucuronidase assay. A chimeric line was determined if one or more shoots were found to be a mixture of transformed cell (in blue) and non-transformed cells (in white). 

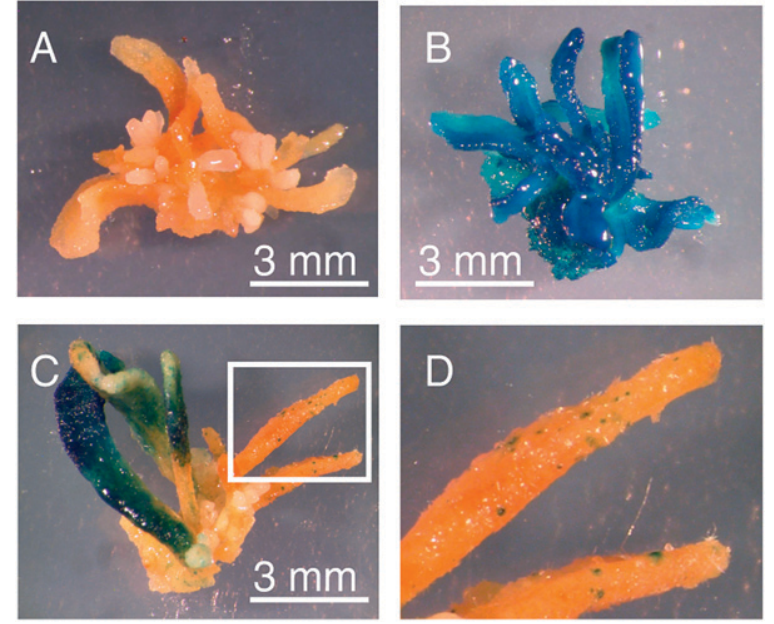

Fig. 1. $\beta$-glucuronidase (GUS) staining patterns of primary regenerated shoots. (A) Escape or nontransgenic shoot with no GUS staining (white); (B) pure transgenic shoot with homogenous GUS staining (blue); (C) chimeric shoot with patched and spotty GUS stain patterns; (D) magnified image of the square area in $\mathbf{C}$ showing the spotty pattern of GUS stain.
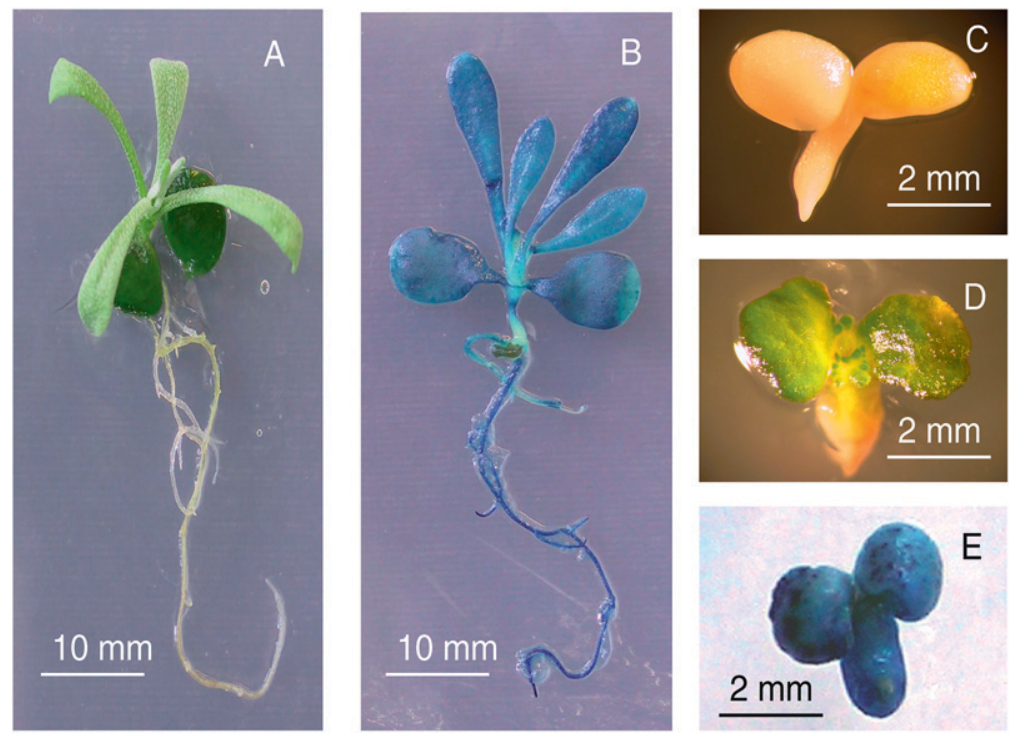

Fig. 2. Phenotype of 2-week-old $\mathrm{T} 1$ seedlings. (A) A hyg ${ }^{\mathrm{R}}$ seedling; (B) a hyg ${ }^{\mathrm{R}}$ seedling showing $\beta$-glucuronidase-positive (GUS+) stain; $(\mathbf{C})$ a hyg ${ }^{\mathrm{S}}$ seedling killed by hygromycin; (D) a partial hyg ${ }^{\mathrm{R}}$ seedling showing arrested growth; $(\mathbf{E})$ a partial hyg ${ }^{\mathrm{R}}$ seedling with GUS+ stain.
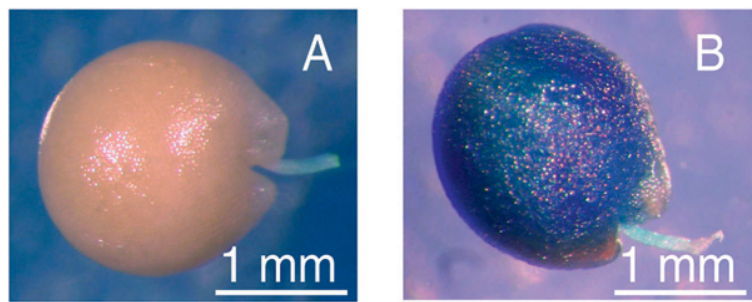

Fig. 3. Segregation of the $\beta$-glucuronidase (GUS) transgene in T2 seeds derived from Line 344 showing a GUS-positive (GUS+) seed (A) and a GUS-negative (GUS-) seed (B).

two hptII insertion loci. In Lines 319 and 322, which had only 24 and 28 seeds germinated, respectively, all showed hyg $^{\mathrm{R}}$ phenotype; their ratios of hyg $^{\mathrm{R}}: \mathrm{hyg}^{\mathrm{S}}$ was considered greater than 15:1. Therefore, these two lines were placed in a category of having more than two transgene insertions. However, this classification might not be conclusive, because at least 64 seeds are required for the characterization of three loci.

In addition, a partial hyg ${ }^{\mathrm{R}}$ phenotype in seven of $35 \mathrm{~T} 1$ progenies of Line 378 was
Table 2. T1 progeny numbers and segregation ratios of hygromycin-resistant $\left(\mathrm{hyg}^{\mathrm{R}}\right)$ and hygromycin-sensitive $\left(\right.$ hyg $^{\mathrm{S}}$ ) phenotype. $^{\mathrm{z}}$

\begin{tabular}{ccccc}
\hline T1 & $\begin{array}{c}\text { Total } \\
\text { no. of }\end{array}$ & $\begin{array}{c}\text { No. of } \\
\text { germinated }\end{array}$ & $\begin{array}{c}\text { hyg }^{\mathrm{R}} \text { hyg }^{\mathrm{S}} \\
\text { seedlings }\end{array}$ & $\begin{array}{c}\text { No. of } \\
\text { hptII gene } \\
\text { insertion }\end{array}$ \\
\hline 149 & 51 & 40 & $31: 9$ & 1 \\
174 & 19 & 13 & $10: 3$ & 1 \\
178 & 58 & 55 & $41: 14$ & 1 \\
213 & 39 & 31 & $24: 7$ & 1 \\
312 & 50 & 46 & $34: 12$ & 1 \\
319 & 29 & 24 & $24: 0$ & $>2$ \\
322 & 33 & 28 & $28: 0$ & $>2$ \\
324 & 18 & 17 & $13: 4$ & 1 \\
344 & 14 & 13 & $10: 3$ & 1 \\
350 & 27 & 18 & $17: 1$ & $\geq 2$ \\
376 & 44 & 39 & $37: 2$ & 2 \\
378 & 36 & 35 & $33^{\mathrm{y}}: 2$ & 2 \\
\hline
\end{tabular}

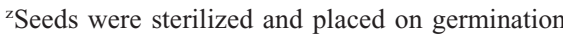
medium plus $50 \mathrm{mg} \cdot \mathrm{L}^{-1}$ hyg, hyg ${ }^{\mathrm{R}}$, or hyg ${ }^{\mathrm{S}}$ seedlings were documented after 2 weeks of culture in a growth chamber. A typical hyg ${ }^{\mathrm{R}}$ seedling had normal cotyledons and true leaf and roots (Fig. 2A), whereas a hyg seedling showed bleached cotyledons and radicle (Fig. 2C).

${ }^{y}$ Seven of the hyg $^{\mathrm{R}}$ seedlings had partial hyg ${ }^{\mathrm{R}}$ phenotype showing small green cotyledons and swelled radicle but no true leave (Fig. 2E).

observed. The partial hyg ${ }^{\mathrm{R}}$ seedlings were arrested on the hygromycin medium, showing small green cotyledons, swelled radicle, and no true leaf and root development (Fig. 2D). The phenotype could be an indication of hptII gene malfunction. Theoretically, if one of the two unlinked hptII genes lost its full function resulting in a partial phenotype, the segregation ratio of hyg ${ }^{\mathrm{R}}$ :partial hyg ${ }^{\mathrm{R}}$ : hyg $^{\mathrm{S}}$ would be 24:6:2. In the case of Line 378, the observed ratio is $26: 7: 2$, suggesting that it could be the result of a malfunctioning copy of the hptII gene. Detailed sequence and biochemistry analyses on the hptII gene in Line 375 are required to confirm the existing of a malfunction copy of the hptII gene.

The numbers of insertion loci of the hptII gene estimated by these genetic segregation analyses in the T1 seedlings of these 12 lines were consistent with the copy numbers of the hptII gene determined by using a quantitative polymerase chain reaction method (Chen and Lin, 2010).

Because the hptII gene is constructed next to a gusA gene in pCAMBIA1301.1, the two genes would most likely segregate together. To confirm the cosegregation, $\approx 50 \%$ of the normal hyg ${ }^{\mathrm{R}}$ seedlings from each line (total 149), including the seven partial hyg ${ }^{\mathrm{R}}$ seedlings from Line 378, were tested by incubating whole seedlings in GUS assay solution. The remaining hyg ${ }^{\mathrm{R}}$ seedlings were tested for GUS activity by leaf disc assay. Positive GUS staining was observed in all seedlings (Figs. 2B and 2E) and leaf discs tested. The results indicated that at least one copy of the gusA gene cosegregated with the hptII in all lines, including these seven partial hyg ${ }^{\mathrm{R}}$ seedlings.

The hyg ${ }^{\mathrm{R}}$ seedlings after leaf disc assay remained healthy and were transplanted to soil for $\mathrm{T} 2$ seed production. At the midmaturation stage of 2 seed development ( $35 \mathrm{~d}$ after 
pollination) (Chen et al., 2009), the stability of transformation was determined by GUS activity assay. GUS positive (GUS+) T2 seeds were observed in all 136 plants representing 12 T1 lines. Some of the T1 plants were heterozygous and the gusA gene segregated in their developed T2 seeds, showing some GUS+ and some GUS-negative (GUS-). Examples of GUS+ or GUS- T2 seed from Line 344 are shown in Figures 3A and 3B, respectively.

\section{Discussion}

In many plant species, in vitro shoot regeneration is a prerequisite and often a limiting step for transformation. In L. fendleri, sufficient shoot regeneration from various tissue types have been reported, including cultured cells (Skarzhinskaya et al., 1996), leaf segments (Skarjinskaia et al., 2003), and explants of hypocotyls and cotyledons (Wang et al., 2008). Leaf was chosen for transformation because it is abundant and can be grown aseptically for continued supply of material. When leaf segments were treated with AGL1/ pCAMBIA1301.1 and under hygromycin selection, $22.5 \%$ and $60.0 \%$ of them generated hyg $^{\mathrm{R}}$ shoots within 8 to 12 weeks (Table 1). This represents improved efficiency compared with a previous published study, which reported an average frequency of hyg ${ }^{\mathrm{R}}$ shoot regeneration from infected calli of $22.7 \%$ (Wang et al., 2008).

Chimeras can give rise to non-transgenic progenies and thus loss of transformants. In L. fendleri, regeneration of chimeras was reported (Skarjinskaia et al., 2003; Wang et al., 2008), but the frequency is not entirely clear. By using gusA as a visual marker, $81.1 \%$ to $89.3 \%$ of primary shoots were found to be chimeras. To eliminate chimeras, a first approach was tried by increasing hygromycin concentration to $50 \mathrm{mg} \cdot \mathrm{mL}^{-1}$ in the CSI medium during the initial culture of leaf segments and the selection of hyg $^{\mathrm{R}}$ calli. However, it had no effect on reducing the number of chimeras (data not shown). In fact, it dropped the speed and occurrence of hyg ${ }^{\mathrm{R}}$ calli and subsequent primary shoot production eight- to 10 -fold. This phenomenon is probably the result of the inhibitory effect of hygromycin during the onset of regeneration (Hanhineva and Karenlampi, 2007; Olhoft et al., 2003). Thereafter, to maximize the number of independently transformed events and to enhance transgenic selection, a higher hygromycin concentration in the medium was used only after primary calli/shoots were obtained. By using multiple rounds of shoot regenerations, a significant reduction of chimeras was achieved from $81.1 \%$ to $89.3 \%$ to $28.9 \%$ to $34.2 \%$ after the second round and to $4.3 \%$ to $6.3 \%$ after the third round. Although two to three rounds of regenerations were recommended to reduce chimeras in tobacco (Maliga and Nixon, 1998) and in strawberry (Mathews et al., 1995), four rounds of regenerations were performed in L. fendleri, because it reduces chimeric shoots further to $1.4 \%$ to $2.2 \%$ (Table 1 ). Each round of L. fendleri shoot regeneration usually takes 2 weeks, so the whole selection process can be optimized to 8 weeks, which is a reasonable length of time for transgenic selection. Under these conditions, most T0 transgenic plants were morphologically normal and capable of producing transgenic seeds (T1).

The phenomenon of chimera production has been reported in many dicotyledonous species in Agrobacterium-mediated transformation and the shoot regeneration process such as cotton (Firoozabady et al., 1987), tobacco (Schmulling and Schell, 1993), soybean (Christou, 1990), flax (Dong and McHughen, 1993), strawberry (Mathews et al., 1995), citrus (Dominguez et al., 2004), and Vigna mungo (Muruganantham et al., 2007). In some of the cases, the frequency of chimera was high, $45 \%$ in citrus (Dominguez et al., 2004) and 80\% in Vigna mungo (Muruganantham et al., 2007). The formation of chimeras has been investigated in detail in tobacco (Schmulling and Schell, 1993), soybean (Christou, 1990), and citrus (Dominguez et al., 2004). Several mechanisms have been proposed to explain the generation of chimeras, including 1) a shoot organ originating from a mixture of transformed and untransformed cells; 2) transformation effects in a cell or cells that either cease to divide or divide to daughter cells forming only a sector in a shoot; and 3) transient expression of a transgene occurring in many cells of a shoot. Although the exact reason of chimera formation in $L$. fendleri remains unknown, patterns of chimeras observed resemble those in soybean and citrus such as sectorial chimeras and spotty single cell chimeras (Fig. 1C-D), which indicates that similar mechanisms might be involved. If a shoot was composed of both transformed and untransformed cells, the untransformed cells could be protected through efficient detoxification of the antibiotic by the transformed cells (Christou, 1990; Dominguez et al., 2004; Schmulling and Schell, 1993). Such cross-protection is certainly possible in $L$. fendleri, because most escapes seem to arise close to or from chimeric calli (picture not shown). Nevertheless, the successive shoot regeneration process as demonstrated is a feasible strategy to overcome cross-protection by removing chimeric cells or purifying isogenic transgenic cells.

The transformation system presented allows generation of stable transgenic plants, and it is an effective protocol to engineer $L$. fendleri as a superior crop for high yield, disease resistance, and other favorable agronomic traits.

\section{Literature Cited}

Caupin, H.J. 1997. Products from castor oil: Past, present and future, p. 787-795. In: Gunstone, F.D. and F.B. Padley (eds.). Lipid technologies and application. Marcel Dekker, New York, NY.

Chen, G.Q. and J.-T. Lin. 2010. Use of quantitative PCR for determining copy numbers of transgenes in Lesquerella fendleri. American Journal of Agricultural and Biological Sciences. 5: 415-421.
Chen, G.Q., L. Vang, and J.T. Lin. 2009. Seed development in Lesquerella fendleri (L.). HortScience 44:1415-1418.

Christou, P. 1990. Morphological description of transgenic soybean chimeras created by the delivery, integration and expression of foreign DNA using electric discharge particle acceleration. Ann. Bot. (Lond.) 66:379-386.

Dierig, D.A., N.R. Adam, B.E. Mackey, G.H. Dahlquist, and T.A. Coffelt. 2006. Temperature and elevation effects on plant growth, development, and seed production of two Lesquerella species. Ind. Crops Prod. 24:1725.

Dierig, D.A., A.E. Thompson, and F.S. Nakayama. 1993. Lesquerella commercialization efforts in the United States. Ind. Crops Prod. 1:289293.

Dierig, D.A., P.M. Tomasi, and G.H. Dahlquist. 2001. Registration of WCL-LY2 high oil Lesquerella fendleri germplasm. Crop Sci. 41: 604-605.

Dierig, D.A., P.M. Tomasi, A.M. Salywon, and D.T. Ray. 2004. Improvement in hydroxy fatty acid seed oil content and other traits from interspecific hybrids of three Lesquerella species: Lesquerella fendleri, L. pallida, and $L$. lindheimeri. Euphytica 139:199-206.

Dominguez, A., R. Cervera, and R.M. Perez. 2004. Characterization of regenerants obtained under selective condition after Agrobacteriummediated transformation of citrus explants reveals production of silenced and chimeric plants at unexpected high frequency. Mol. Breed. 14:171-183.

Dong, J.Z. and A. McHughen. 1993. Transgenic flax plants from Agrobacterium mediated transformation: Incidence of chimeric regenerants and inheritance of transgenic plants. Plant Sci. 91:139-148.

Firoozabady, E., D.L. DeBoer, D.J. Merlo, E.L. Halk, L.N. Amerson, K.E. Rashka, and E.E. Murray. 1987. Transformation of cotton (Gossypium hirsutum L.) by Agrobacterium tumefaciens and regeneration of transgenic plants. Plant Mol. Biol. 10:105-116.

Hanhineva, K.J. and S.O. Karenlampi. 2007. Production of transgenic strawberries by temporary immersion bioreactor system and verification by TAIL-PCR. BMC Biotechnol. $7: 1-12$

Hayes, D.G. and R. Kleiman. 1996. A detailed triglyceride analysis of Lesquerella fendleri oil: Column chromatographic fractionation followed by supercritical fluid chromatography. Journal of the American Oil Chemists' Society 73:267-269.

Isbell, T.A., M.S. Mund, R.L. Evangelista, and D.A. Dierig. 2008. Method for analysis of fatty acid distribution and oil content on a single Lesquerella fendleri seed. Ind. Crops Prod. 28: 231-236.

Jefferson, R.A., T.A. Kavanagh, and M.W. Bevan. 1987. GUS fusions: Beta-glucuronidase as a sensitive and versatile gene fusion marker in higher plants. EMBO J. 6:3901-3907.

Lazo, G.R., P.A. Stein, and R.A. Ludwig. 1991. A DNA transformation-competent Arabidopsis genomic library in Agrobacterium.. Nat. Biotechnol. 9:963-967.

Maliga, P. and P.J. Nixon. 1998. Judging the homoplastomic state of plastid transformants. Trends Plant Sci. 3:376-377.

Mathews, H., W. Wagoner, J. Kellogg, and R. Bestwick. 1995. Genetic transformation of strawberry: Stable integration of a gene to control biosynthesis of ethylene. In Vitro Cell. Dev. Biol. Plant. 31:36-43. 
Murashige, T. and F. Skoog. 1962. A revised medium for rapid growth and bioassays with tobacco tissue cultures. Physiol. Plant. 15:473-497.

Muruganantham, M., S. Amutha, N. Selvaraj, G. Vengadesan, and A. Ganapathi. 2007. Efficient Agrobacterium-mediated transformation of Vigna mungo using immature cotyledonarynode explants and phosphinothricin as the selection agent. In Vitro Cell. Dev. Biol. Plant. 43:550-557.

Olhoft, P.M., L.E. Flagel, C.M. Donovan, and D.A. Somers. 2003. Efficient soybean transformation using hygromycin B selection in the cotyledonary-node method. Planta 216:723735 .

Schmulling, T. and J. Schell. 1993. Transgenic tobacco plants regenerated from leaf disks can be periclinal chimeras. Plant Mol. Biol. 21: 705-708.

Skarzhinskaya, M., M. Landgren, and K. Glimelius. 1996. Production of intertribal somatic hybrids between Brassica napus L. and Lesquerella fendleri (Gray) wats. Theor. Appl. Genet. 93: 1242-1250.

Skarjinskaia, M., Z. Svab, and P. Maliga. 2003. Plastid transformation in Lesquerella fendleri, an oilseed Brassicacea. Transgenic Res. 12: 115-122.

Smith C.R., Jr., T.L. Wilson, T.K. Miwa, H Zobel, R.L. Lohmar, and I.A. Wolff. 1961. Lesquerolic acid. A new hydroxy acid from Lesquerella seed oil. J. Org. Chem. 26:29032905.

Wang, W., C. Wang, B.L. Huang, and B. Huang. 2008. Agrobacterium tumefaciens-mediated transformation of Lesquerella fendleri L. a potential new oil crop with rich lesquerolic acid. Plant Cell Tissue Organ Cult. 92:165171. 